\title{
Biotin Derivatives Carrying Two Chelating DOTA Units. Synthesis, in Vitro Evaluation of Biotinidases Resistance, Avidin Binding, and Radiolabeling Tests
}

\author{
Alessandro Pratesi, ${ }^{\dagger}$ Francesca Bucelli, ${ }^{\dagger}{ }^{\oplus}$ Ilaria Mori, ${ }^{\dagger, \#}$ Marco Chinol, ${ }^{\S}$ Antonio Verdoliva, ${ }^{\ddagger}$ Giovanni Paganelli, ${ }^{\S}$ \\ Vincenzo Rivieccio, ${ }^{*}$ Lucia Gariboldi, ${ }^{\S}$ and Mauro Ginanneschi*, ${ }^{\dagger}$ \\ †Laboratory of Chemistry and Biology of Peptides and Proteins, Department of Organic Chemistry "Ugo Schiff", Via della Lastruccia 13, \\ 50019 Sesto Fiorentino, Firenze, Italy, ${ }^{\S}$ European Institute of Oncology (IEO), Via Ripamonti 435, 20141 Milano, Italy, and ${ }^{\star}$ Research and \\ Development, Biochemistry Unit, Tecnogen S.p.A., Località La Fagianeria, 81013, Piana di Monte Verna, Caserta, Italy. " Present address:

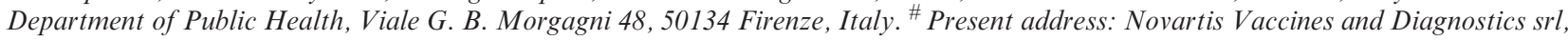 \\ Via Fiorentina 1, 53100 Siena, Italy.
}

Received September 22, 2009

The synthesis of four biotin derivatives carrying two DOTA moieties for each ligand (BisDOTA set) is
reported, for increasing radiation/dose ratio and improving efficiency in the pretargeted avidin-biotin
radioimmunotherapy. The biotin-containing scaffold of two BisDOTA was similar to the mono-DOTA
derivative previously described. Then the scaffold was elongated by trifunctionalized spacers of
different length and conjugated with one of the COOH groups of two DOTA. Two others were
prepared starting from a on-resin lysine residue. The lysine $\alpha$-NH $\mathrm{Na}_{2}$ was bonded to biotin, and then
spacers were appended to the $\varepsilon-\mathrm{NH}_{2}$ and conjugated with two DOTA molecules. One compound
contained a $p$-aminobenzoic acid spacer, which ensured higher head-to-tail distance and increased
rigidity of the chain. These last two compounds had a very high ability to bond avidin and were labeled
with ${ }^{90} \mathrm{Y}$ at high specific activity. All the compounds were resistant to the action of serum biotinidases.

\section{Introduction}

Tumor therapy is mostly implemented through the use of substances targeted at destroying cancer cells. This can be achieved with cytotoxic substances, which have to penetrate into the tumor cells in order to exert their full effect or by means of treatment of the tumor cells with radiation of sufficient energy to kill the cells. In both cases the main problem is to deliver the substance in a selective manner to the target cells to avoid possible damage to the surrounding healthy cells. The very high binding affinity of (+)-biotin toward the xenobiotic proteins avidin (Av) and streptavidin $(\mathrm{Sav})^{1}$ prompted researches in multidiscipcilinary fields to address the use of labeled biotin derivatives, in combination with Av or Sav and monoclonal antibodies (MoAbs), for delivering diagnostic or therapeutic radionuclides to cancer cells. ${ }^{2}$ Actually, the so-called pretargeting protocols are widely used in the clinical practice ${ }^{3-8}$ and, among them, the flexible three-steps method appeared especially useful for therapy of several type of tumors. ${ }^{7,-13}$ In designing new biotin conjugates for pretargeted radiotherapy of cancer, one must take in account that amide bonds between the valeric acid side arm of biotin and the spacer carrying the radiolabeled moiety could be degraded by the action of the serum biotinidases. ${ }^{14}$ At the same time, molecular changes of the biotin side arm, carrying the radionuclide chelating unity, can affect the binding to $\mathrm{Av}$ or Sav, diminishing the affinity and causing loss of the radiating potency on cancer cells. The pivotal work of Wilbur's group ${ }^{14,15}$ and of other researchers ${ }^{16}$ has highlighted

*To whom correspondence should be addressed. Phone: +39055 4573525. Fax: +39055 4573531. E-mail: mauro.ginanneschi@unifi.it. some structural characteristics of the biotin conjugates which hamper the action of biotinidase and allow retention of high affinity for Av and Sav pockets. Recently, J. Hainsworth et al. demonstrated that DOTA ${ }^{a}-(\alpha)$-biotinamidolysine (Chart 1) is $93 \%$ streptavidin bound and that this molecule shows high stability in serum. ${ }^{17}$ On the other hand, Pazy et al. showed that the Av pocket is much more sensible than Sav to structural changes on the biotin side chain, which caused the disordered conformation of a critical loop. ${ }^{18}$ On the basis of these findings, these authors suggested an explanation of the fundamental role of streptavidin when administred in the three-step procedure. ${ }^{13,14}$ Recently, we prepared a new biotin-monoDOTA conjugate, r-BHD (Chart 2), ${ }^{19}$ where the original carboxy group of the biotin was bonded to diaminohexane, then the amide $\mathrm{CO}$ reduced to $\mathrm{CH}_{2}$ group, and finally, the $\mathrm{N}$ hexylamine coupled to one of the four carboxymethyl chains of DOTA chelator. Preclinical evaluations (radiolabeling studies, binding to $\mathrm{Av}$, and in vitro stability of the ${ }^{90} \mathrm{Y}$ labeled

\footnotetext{
${ }^{a}$ Abbreviations: DOTA 1,4,7,10-tetraazacyclododecane- $N, N^{\prime}, N^{\prime \prime}$, $N^{\prime \prime \prime}-1,4,7,10$-tetraacetic acid; DIPEA, diisopropylethylamine; DMF, dimethylformamide; DMSO- $d_{6}$, hexadeuteriodimethyl sulfoxide; DTPA, diethylenetriaminepentaacetic acid; EDC, 1-(3-dimethylaminopropyl)-3ethylcarbodiimide; FCC, fast column chromatography; Fmoc, $9 H$-fluoren-9-ylmethyloxycarbonyl; HABA, 4'-hydroxyazobenzene-2-carboxylic acid; HATU, 1-[bis(dimethylamino)methylene]-1H-1,2,3-triazole(4,5b)pyridium-3-oxide hexafluorophosphate; HOBt, 1-hydroxybenzotriazole; ITLC-SC, silica gel instant thin layer chromatography; MTT, methyltrityl; NMM, $N$-methylmorpholine; NMP, 1-methyl-2-pyrrolidinone; NMS, normal mouse serum; RCP, radiochemical purity; SPE, solid phase extraction; sulfo-NHS, $N$-hydroxysulfosuccinimide sodium salt; TBTU, 1-[bis(dimethylamino)methylene]- $1 H$-benzotriazolium-3oxide tetrafluoroborate; TFA, trifluoroacetic acid; THF, tetrahydrofurane; TIS, triisopropylsilane.
} 
complex) suggested that this bioconjugate is a good candidate for future applications in pretargeting protocols. ${ }^{19}$ However, in the three-step pretargeting technique, the radioactivity is carried on the tumor by the radiolabeled biotin functionalized with the suitable chelating agent. Since only a small percentage really localizes on the tumoral lesion, it is important that the DOTA-biotin conjugate is labeled at high specific activity. The maximum allowed stoichiometry of a DOTA conjugated molecule is one metallic radionuclide per molecule, and this may limit the dose effectively delivered to the tumor. This prompted us to synthesize and test new biotin derivatives,

Chart 1. Carboxylate Function $\alpha$ to the Biotinamide

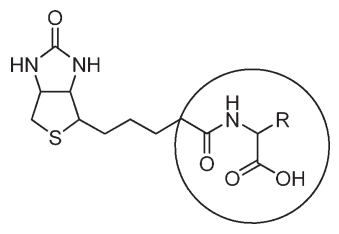

Chart 2. Structure of r-BHD<smiles>O=C(O)CN1CCN(CC(=O)O)CCN(CC(=O)NCCCCCCNCCCCCC2SCC3NC(=O)NC32)CCN(CC(=O)O)CC1</smiles>

carrying two DOTA groups per molecule (BisDOTA set). Substantially, BisDOTA are biotins modified through bifunctional spacers of different lengths and chemical structures, conjugated with two molecules of DOTA. Our aim was to label the BisDOTA set at higher specific activity than the mono-DOTA analogue, r-BHD. In fact, each BisDOTA can theoretically bind up to two radionuclide ions. In this way, the radiolabeled derivatives could deliver a higher radiation dose to the tumor and then improve the efficiency of targeted radionuclide therapy, provided the affinity for Av is retained at the highest level. We report herewith the synthesis of these new biotin derivatives featured by spacers chosen with the aim to have a suitable distance between the bulky DOTA chelating groups and, at the same time, between them and the biotine head (Schemes 1, 3, and 4). While two of the new derivatives (5a and 5b) were prepared starting from the previously reported biotin $\mathrm{N}$-hexylamino derivative, precursor of $\mathrm{r}$ BHD (Schemes 1 and 3), the other compounds 12 and 16 were obtained by conjugation of biotin with the $\alpha-\mathrm{NH}_{2}$ of a Lys molecule via solid phase peptide synthesis (SPPS) strategy (Scheme 4). The avidin binding ability of BisDOTA derivatives was experimentally investigated by competitive binding studies with HABA/avidin complex, testing the thermal stability of Av/BisDOTA complexes by using CD spectroscopy. The Lys containing BisDOTA/avidin complexes showed an excellent stability when compared to the native $(+)$-biotin.

Scheme 1. Synthesis of BisDOTA-C 3

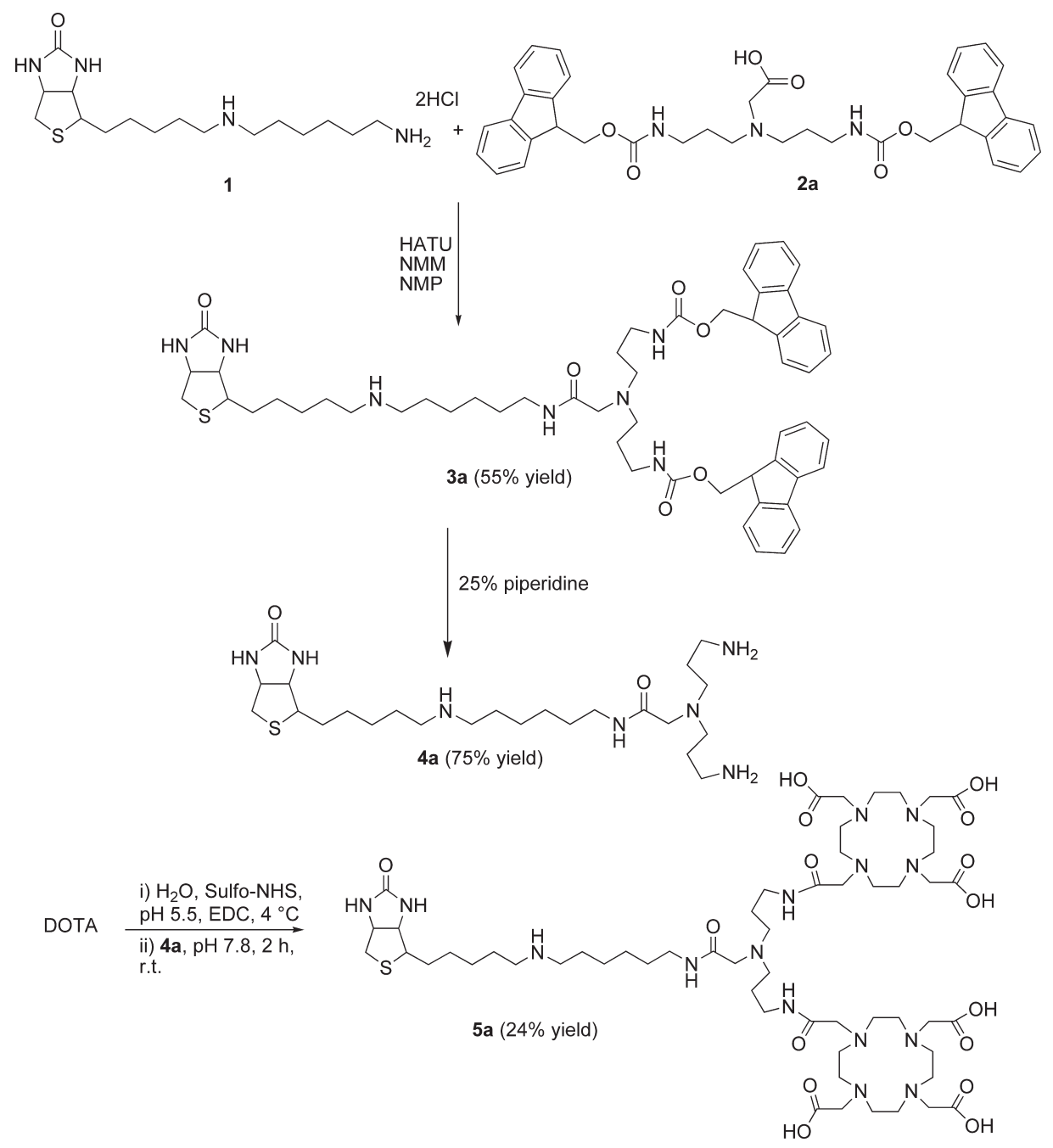


Scheme 2. Synthesis of the Fmoc-Protected Spacer $\mathrm{C}_{6}(\mathbf{2 b})$
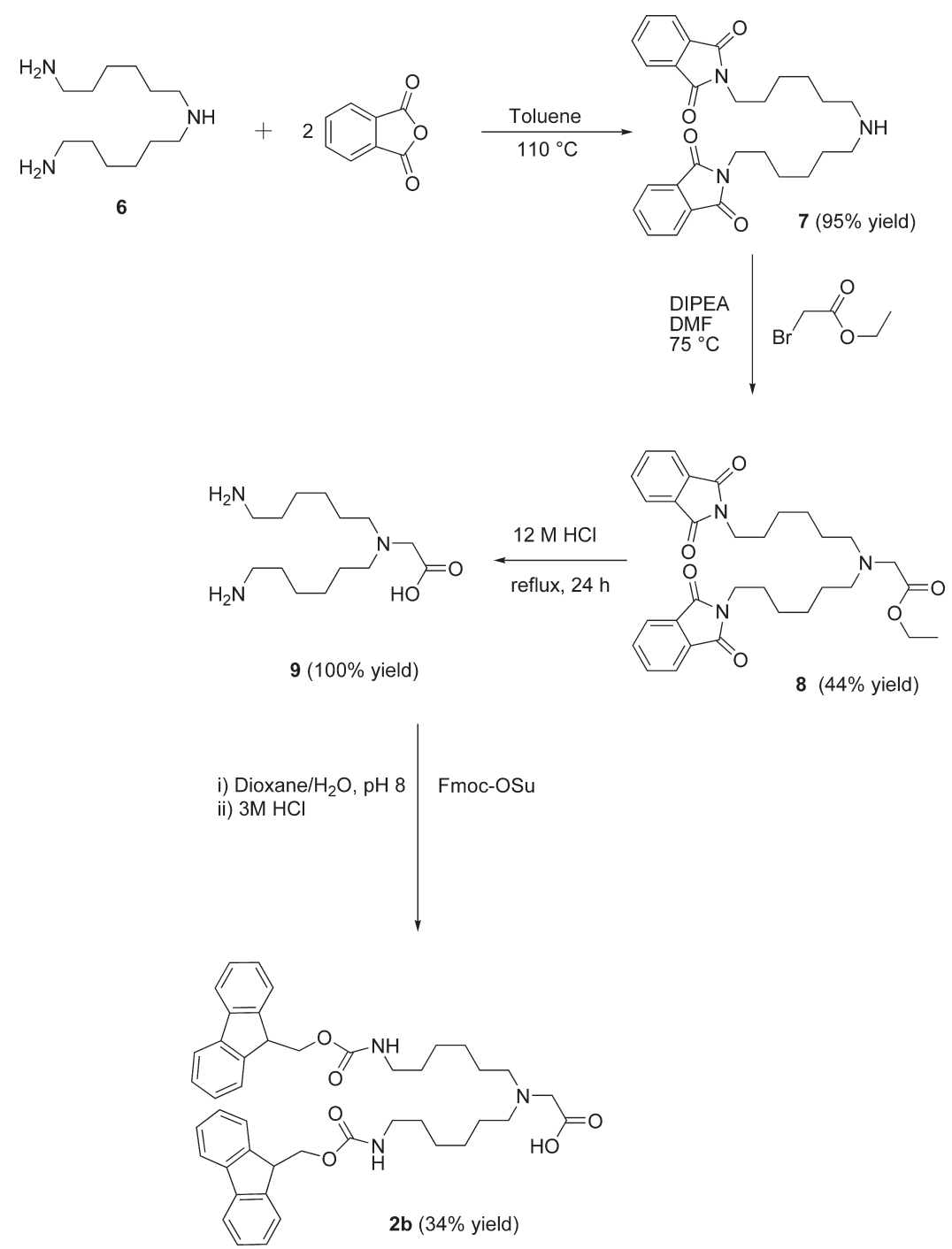

Moreover, biotinidase stability assay was also performed on these compounds, giving for all BisDOTA the expected good results.

\section{Results and Discussion}

Synthesis. BisDOTA derivative 5a was prepared starting from the $N$-hexylaminobiotinyl amine 1 (Scheme 1) that was insensitive to the action of biotinidases. ${ }^{19}$ The spacer 2 a was then introduced on the amino side arm for appending the two DOTA moieties. Notably, the spacer lengths were chosen in order to avoid the two chelating groups hanging too far away from the avidin pocket. The first spacer, $\mathbf{2 a}$, is commercially available as hydrogen sulfate salt. All the reaction steps were carried out in solution. Because of the low solubility of $\mathbf{1}$ in the commonly used organic solvents, the coupling with $\mathbf{2 a}$ was carried out in NMP. The carboxy group of the spacer $\mathbf{2 a}$ was activated by the uronium (aminium) salt before the addition of the amino component. ${ }^{20}$ Moreover, the coupling requires basic conditions, and the use of the tertiary base NMM avoids reaction with the $\mathbf{2 a}$ active ester. However, only 1 mol equiv of NMM was used for leaving most of the secondary NH protected as the hydrochloric acid salt. In the Fmoc deprotection of compound $\mathbf{3 a}$, piperidine should be accurately washed away because in the next step this base can compete in the coupling with the activated DOTA. This latter was activated following the method reported for the synthesis of $\mathrm{r}$-BHD. ${ }^{19}$ In order to minimize the risk of reaction on the secondary amine group, the coupling was performed at $\mathrm{pH} 7.8$, and the presence of the free NH group in the final product $\mathbf{5 a}$ was detected by NMR spectrum and confirmed by the Feigl spot test. ${ }^{19}$ The synthesis of the BisDOTA homologue, $\mathbf{5 b}$, required the preparation of the new $\mathrm{C}_{6}$-chain spacer, $\mathbf{2} \mathbf{b}$, that was obtained starting from the bis-(6-aminohexyl)amine $\mathbf{6}$ and following the method reported by Bambino et al. for the preparation of $\mathbf{2} \mathbf{b},{ }^{21}$ by means of an appropriate protection/deprotection sequence (Scheme 2). In the ESI spectrum of $\mathbf{2} \mathbf{b}$, the peak corresponding to $m / z 1435.1$ is a Fmoc-mediated cluster due to the experimental ionization and disappears in the MS-MS spectrum carried out with soft ionization conditions for avoiding fragmentation of the molecular peak. Ongoing from this step, the reaction pathway for the preparation of BisDOTA-C 6 followed the same procedure as for BisDOTA$\mathrm{C}_{3}$ (5a), affording the expected compound $\mathbf{5 b}$ in higher yields than the corresponding $\mathrm{C}_{3}$-derivative (Scheme 3 ). In compounds $\mathbf{5 a}, \mathbf{b}$, the DOTA chelating groups are bonded to the biotinylated moiety by means of one of the four acetic acid side chains. We demonstrated in our preceding paper ${ }^{19}$ that 
Scheme 3. Synthesis of BisDOTA- $\mathrm{C}_{6}$

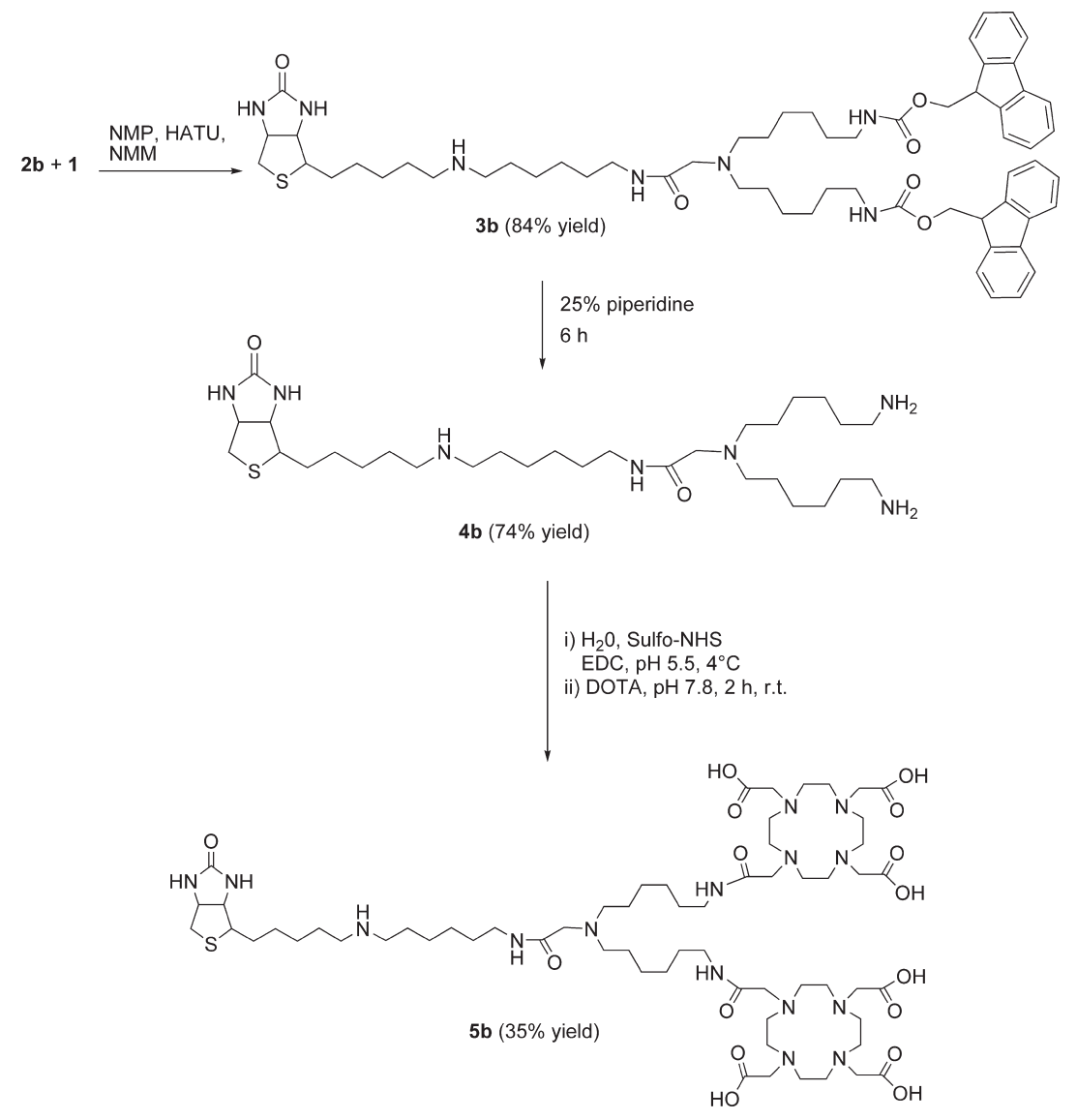

the use of one of the DOTA carboxy groups for the link to the biotinylated moiety did not significantly affected the ability of the azamacrocycle units to chelate the radioactive ions we used in the labeling. As depicted in Schemes 1 and 3, the coupling of DOTA to give compounds $\mathbf{5} \mathbf{a}$ and $\mathbf{5 b}$ was best achieved in aqueous solution by activating the free tetraacetic acid molecule with the water-soluble EDC/sulfo-NHS system. Taking into account the necessity of activating mainly one of the carboxylic acid groups, the solution $\mathrm{pH}$ was 5.5 , as previously described. ${ }^{19}$ This procedure, although giving low yields of the pure BisDOTA-C $\mathrm{C}_{3}$ and BisDOTA- $\mathrm{C}_{6}$ $(25-35 \%)$, is easy to scale up and is cheap. Another critical point of both of these synthetic routes is the preparation of the starting amine $\mathbf{1}$ by reduction of a suspension of the corresponding amide in THF with $\mathrm{BH}_{3}$. THF reagent. This reaction required a time-expensive workup of the crude product, and the final yield is not high. ${ }^{19}$ The finds of Hainsworth et al. on the good affinity of biotin-lysine derivatives carrying one DOTA group for $\operatorname{Sav}^{17}$ suggested us to bond biotin directly with the $\alpha$-amino group of lysine and test the affinity of the so obtained BisDOTA derivatives to Av and, at the same time, their stability toward the biotinidases action. Concerning this latter point, we considered that the presence of two bulky groups like the DOTA moieties, very close each other, should be a barrier against the enzymatic hydrolysis despite the presence of an amide group near the biotin head. On this basis, we were prompted to prepare $\alpha$ biotinamidolysine derivatives by coupling the biotin with $\mathrm{L}-$ lysine suitably protected on the $\varepsilon$-amino group. The introduction of the bifunctional spacer and the conjugation of two DOTA groups completed the synthetic design. Aiming to ensure a fast approach to the final derivatives, we decided to exploit the SPPS, which is routinely used in our laboratory, because this technique can rapidly afford the products and allow an easy scale-up of the synthesis. Moreover, in this technique, at the end of each step, the byproduct can be removed from the solid phase by simple washings.

The preparation of the biotinylated lysine derivatives BisDOTA-Lys- $\mathrm{C}_{3}(\mathbf{1 2})$ and BisDOTA-Lys-(pAB)- $\mathrm{C}_{3}(\mathbf{1 6})$ is outlined in Scheme 4. The orthogonally protected (Fmoc/ MTT) lysine was purchased already bonded to Wang resin. After deprotection of the $\alpha$-amino group by piperidine, only one coupling step with the activated $(+)$-biotin was necessary for the conjugation. Removal of the MTT group and reaction with the Fmoc-protected spacer $\mathbf{2 a}$, easy to hand in SPPS, afforded the protected diamine 11. In another synthetic route, designed to move the bulk of the radiolabeled DOTA moiety further away from the Av pocket, we prepared a longer spacer holding an aromatic, rigid, structure. In this scheme, the on-resin biotinamidolysine was smoothly coupled with $N$-protected $p$-aminobenzoic acid (pAB) which, after deprotection, was, in turn, coupled with 2a giving the bis-amine 15. The poor nucleophilicity of the amino group of $\mathrm{pAB}$ complicated this coupling step and lowered the yields. Different activating agents, especially designed for peptide synthesis, were used in this task. In our conditions, the HATU/NMM method gave the best results. Because the Kaiser test for establishing the level of coupling of the $\mathrm{NH}_{2}$ group of $\mathrm{pAB}$ gave unreliable results, the progress of the reaction was controlled by a series of microcleavages. Finally, after cleavage of the Fmoc protecting groups of $\mathbf{1 1}$ and 15, 4-fold molar excess of tris(tert-butyl) 
Scheme 4. Synthetic Route for BisDOTA-Lys- $\mathrm{C}_{3}(\mathbf{1 2})$ and BisDOTA-Lys-(pAB)-C ${ }_{3}(\mathbf{1 6})$

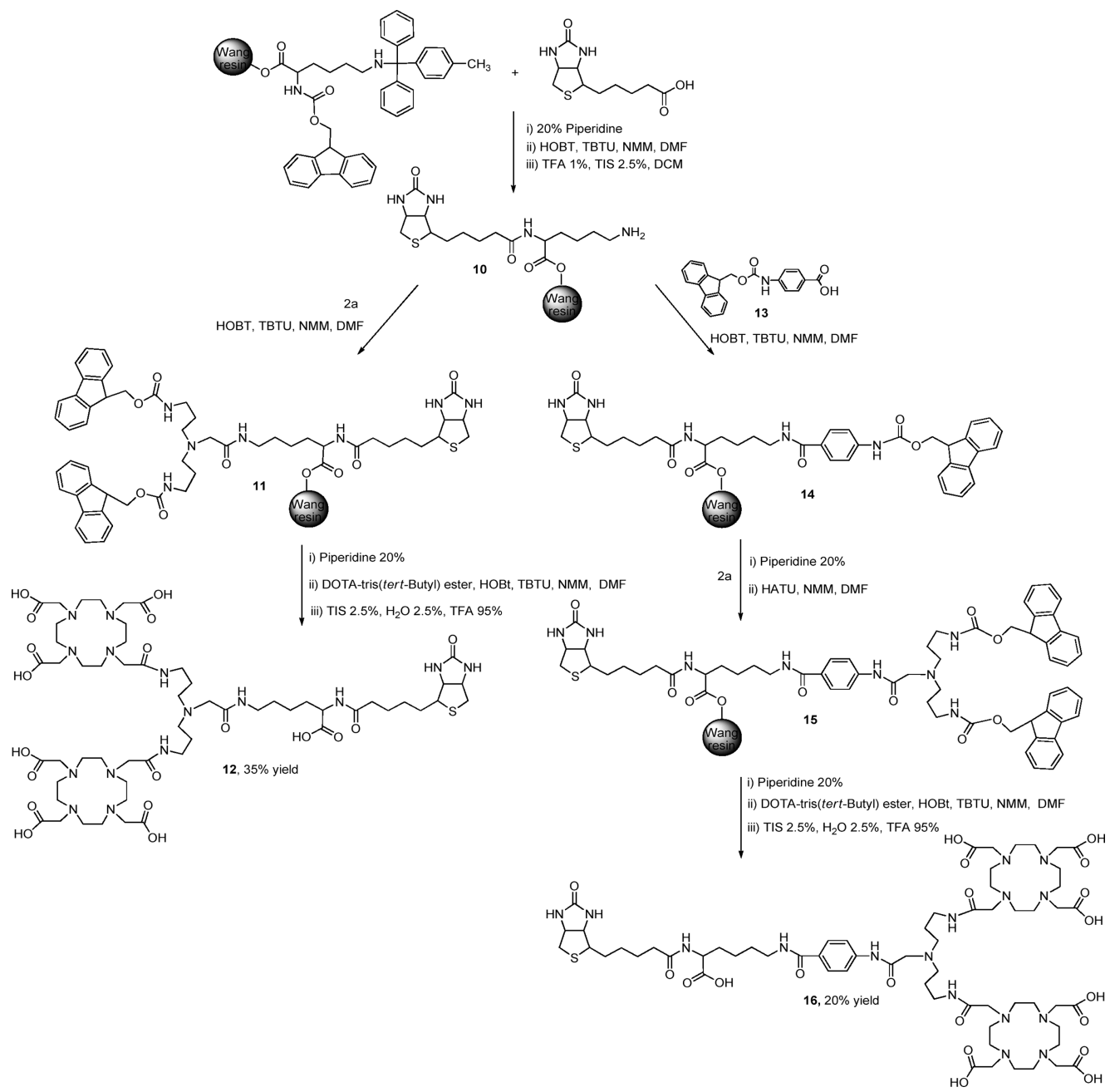

ester of DOTA, well soluble in DMF and activated as reported in Scheme 4, was added giving the required BisDOTA. The on-resin final compounds were cleaved with a solution of $95 \%$ TFA, $2.5 \% \mathrm{H}_{2} \mathrm{O}$, and $2.5 \%$ TIS. Notably, the very high TFA concentration was also able to hydrolyze the tert-butyl ester functions at room temperature $(4-5 \mathrm{~h})$, affording the expected BisDOTA $\mathbf{1 2}$ and $\mathbf{1 6}$ as the free carboxylic acids.

Testing Av Binding Ability and Thermal Stability of Av/ BisDOTA Complexes. The avidin binding activity of BisDOTA derivatives was determined by HABA assay in comparison with $(+)$-biotin. ${ }^{22}$ The assay utilizes the observation that HABA shows dramatic spectral changes when it binds to avidin. Free HABA has an absorption peak at $348 \mathrm{~nm}$, while the HABA/avidin complex has strong absorption at $500 \mathrm{~nm}$. Since the affinity between HABA and avidin is relatively weak $\left(K_{\mathrm{d}}=5.8 \times 10^{-6} \mathrm{M}\right)$ compared to the affinity between $(+)$-biotin and avidin $\left(K_{\mathrm{d}}=1 \times 10^{-15} \mathrm{M}\right),(+)$-biotin can easily replace $\mathrm{HABA}$ from the $\mathrm{HABA} /$ avidin complex, resulting in a decrease of absorption at $500 \mathrm{~nm}$. To estimate the apparent avidin binding affinity of biotin and BisDOTA derivatives, several competitive binding studies have been performed adding (+)-biotin and corresponding BisDOTA derivatives to the $\mathrm{HABA}$ /avidin sample and measuring any change in absorbance. As shown in Figure 1, all BisDOTA compounds were able to inhibit the HABA/avidin complex in a dose dependent manner.
Nevertheless, because of the differences in their spacer arms, BisDOTA-Lys- $\mathrm{C}_{3}(\mathbf{1 2})$ and BisDOTA-Lys-(pAB)- $\mathrm{C}_{3}$ (16) molecules showed an avidin binding capacity stronger than BisDOTA-C $\mathrm{C}_{3}$ and very similar to the native (+)-biotin. For sake of clarity, the relevant HABA displacement abilities are also compared in Table 1, comprising BisDOTA- $\mathrm{C}_{6}$ that is not reported in Figure 1.

In strict agreement with these results, the BisDOTA- $\mathrm{C}_{3}$ interaction with avidin stabilizes the complex, upon heat denaturation, only partially if compared to wild type avidin alone (Figure 2). In fact, the melting curve of avidin/BisDOTA-C ${ }_{3}$ complex shows an inflection point at about $90{ }^{\circ} \mathrm{C}$, which is higher than that of the avidin alone (about $80^{\circ} \mathrm{C}$ ). Indeed, the melting curves of avidin/BisDOTA-Lys- $\mathrm{C}_{3}$ and avidin/BisDOTA-Lys-(pAB)- $\mathrm{C}_{3}$ complexes show no valuable inflection point in the temperature range 25-95 ${ }^{\circ} \mathrm{C}$, similar to avidin $/(+)$-biotin complex.

Results of the Evaluation of the Maximum SA. Three biotin derivatives, namely, 5a, 12, and $\mathbf{1 6}$, were radiolabeled with ${ }^{90} \mathrm{Y}$ at high SA with high RCP. In particular, RCP above $99 \%$ was obtained with a SA of $2.6,5.2$, and $10.6 \mathrm{MBq} / \mathrm{nmol}$. A further increase in SA $(51.2,212,530 \mathrm{MBq} / \mathrm{nmol})$ showed a decrease in RCP but still higher than $95 \%$. The possibility of increasing considerably the specific activity maintaining high RCPs may represent a great advantage in the clinical application of the avidin-biotin system. A new targeted locoregional therapy, based on avidin and ${ }^{90} \mathrm{Y}$ labeled 


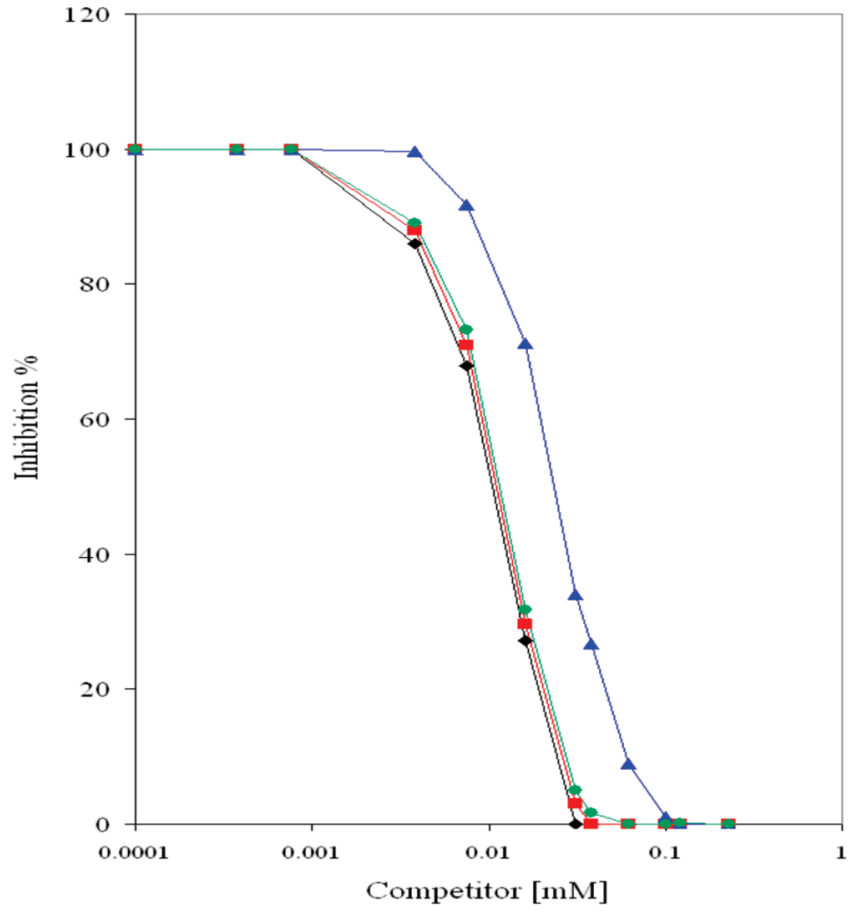

Figure 1. Inhibition of the HABA/avidin complex by (+)-biotin $(\bullet$, black line), BisDOTA-Lys-C 3 ( $\mathbf{\square}$, red line), BisDOTA-Lys-(pAB)- $\mathrm{C}_{3}$ $(\bullet$, green line), and BisDOTA-C 3 ( $(\mathbf{\wedge}$, blue line). Data are representative of three different experiments.

Table 1. Displacement of HABA from Avidin Complex by Biotin and BisDOTA Derivatives $(31 \mu \mathrm{M}, \mathrm{Av} /$ Ligand $=1: 4)$

\begin{tabular}{lc}
\hline \multicolumn{1}{c}{ compd } & HABA/Av inhibition, $\%$ \\
\hline (+)-biotin & 100 \\
BisDOTA-C $_{3}$ & 66 \\
BisDOTA-C $_{6}$ & 64 \\
BisDOTA-Lys-C $_{3}$ & 95 \\
BisDOTA-Lys-(pAB)-C $_{3}$ & 97 \\
\hline
\end{tabular}

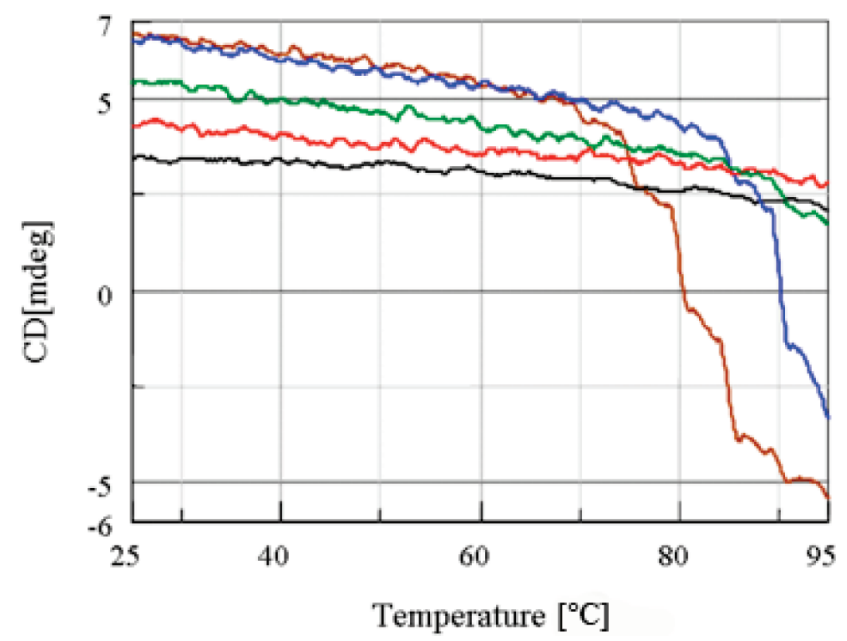

Figure 2. Melting curves of avidin (brown line), avidin/BisDOTA$\mathrm{C}_{3}$ complex (blue line), avidin/BisDOTA-Lys- $\mathrm{C}_{3}$ complex (red line), Avidin/BisDOTA-Lys-(pAB)- $\mathrm{C}_{3}$ complex (green line), and avidin/ $(+)$-biotin complex (black line).

r-BHD, has shown great potential in the treatment of breast cancer reducing the duration of radiotherapy. ${ }^{23}$ In this approach, r-BHD has been labeled at a specific activity of 2.6 MBq/nmol. Using the herein described BisDOTA deri- vatives radiolabeled at high SA may lead to a higher uptake by the targeted tumor area administering lower ${ }^{90} \mathrm{Y}$ activity, thus reducing the radiation burden to nontarget organs.

Stability Assay for Biotinidases. Biocytin is the natural substrate of the biotinidases, a hydrolytic enzyme family normally present in human and mouse sera, involved in the assimilation process of $(+)$-biotin (vitamin $\mathrm{H}$ ) from diet. Activity of biotinidases in freshly collected NMS was assessed by incubating commercial biocytin with NMS, at $37{ }^{\circ} \mathrm{C}$, and verifying the presence of (+)-biotin as product of the reaction. As shown in Figure 3 (panels $\mathrm{A}$ and $\mathrm{B}$, profiles 2 and 3 ), after $2 \mathrm{~h}$ of incubation, biocytin (retention time $12 \mathrm{~min}$; $[\mathrm{M}+\mathrm{H}]^{+}=373.5 \mathrm{Da}$ ) was effectively hydrolyzed to produce a new species, at about $t_{\mathrm{R}}=12.5 \mathrm{~min}$, with a molecular weight $[\mathrm{M}+\mathrm{H}]^{+}=245.1 \mathrm{Da}$, corresponding to (+)-biotin molecular weight (profile 3). Analysis of BisDOTA-Lys-(pAB)-C $\mathrm{C}_{3}$ (16) incubated with NMS for $2 \mathrm{~h}$ at $37^{\circ} \mathrm{C}$ (profile 4) shows that no peak, with a retention time of about $12.5 \mathrm{~min}$ and corresponding to (+)-biotin, appeared, thus underlining the resistance of $\mathbf{1 6}$ to biotinidases activity. In strict agreement with these results, the peak of BisDOTALys-(pAB)- $\mathrm{C}_{3}$ was fully recovered after the incubation step. Similar results were obtained with BisDOTA- $\mathrm{C}_{3},-\mathrm{C}_{6}$, and BisDOTA-Lys- $\mathrm{C}_{3}$ derivatives (data not shown).

\section{Conclusions}

In summary, this study describes the syntheses and characterizations of four new biotin derivatives resistant to the biotinidases action and able to carry two radioisotopes for ligand unit. Radiolabeling experiments with ${ }^{90} \mathrm{Y}$ confirmed the expected achievable high specific activity. Experimental data on the thermal stability of avidin/ligand complexes suggested, at least for the derivatives containing a lysine spacer, a very high affinity for the protein and pointed out the different behavior between the spacers containing or not the lysine chain. Nevertheless, further studies in vitro and in vivo with the labeled BisDOTA will be necessary before considering these compounds good candidates for improving RIT protocols.

\section{Experimental Procedures}

General. DOTA and tris(tert-butyl)-DOTA were purchased from Macrocyclics (Richardson, TX) while standard (+)-biotin (B4639) and biocytin (B4261) were purchased from SigmaAldrich. $N, N$-Bis[3-(Fmoc-amino)propyl]glycin hydrogen sulfate potassium salt (2a) was from Fluka (Sigma-Aldrich, Switzerland). Fmoc-Lys(MTT)-Wang resin (100-200 mesh) was from Novabiochem AG (Laufelfingen, Switzerland), 6-Cl HOBt from Luxembourg (Israel), HATU from PerSeptive Biosystem, and TBTU from Chem Impex International (Wood Dale, IL). Peptide-synthesis grade DMF was from Scharlau (Barcelona, Spain). HPLC-grade $\mathrm{MeCN}$ was purchased from Carlo Erba (Italy). Dry solvents were distilled immediately before use: THF over sodium/benzophenone. All other chemicals were commercial compounds and were used as received. ${ }^{90} \mathrm{Y}$ chloride in hydrochloric acid $(0.04 \mathrm{M})$ was purchased from QSA Global, Braunschweig, Germany. HABA was from SigmaAldrich (Switzerland) and avidin from Tecnogen (Italy). ${ }^{1} \mathrm{H}$ NMR spectra were recorded on a Varian Gemini $200 \mathrm{MHz}$ or Varian Inova $400 \mathrm{MHz}$ spectrometer in DMSO- $d_{6}, \mathrm{D}_{2} \mathrm{O}$, or $\mathrm{CDCl}_{3}$. Chemical shifts are reported in ppm $(\delta)$ downfield from tetramethylsilane. CD spectra were acquired on Jasco J-715 spectropolarimeter equipped with a thermostatic water bath. Electrospray ionization mass spectra (ESI-MS) were acquired on LCQ-Advantage ESI ion trap spectrometer (Thermo Finnigan) for positive and negative ions detection. Fast atom 
A

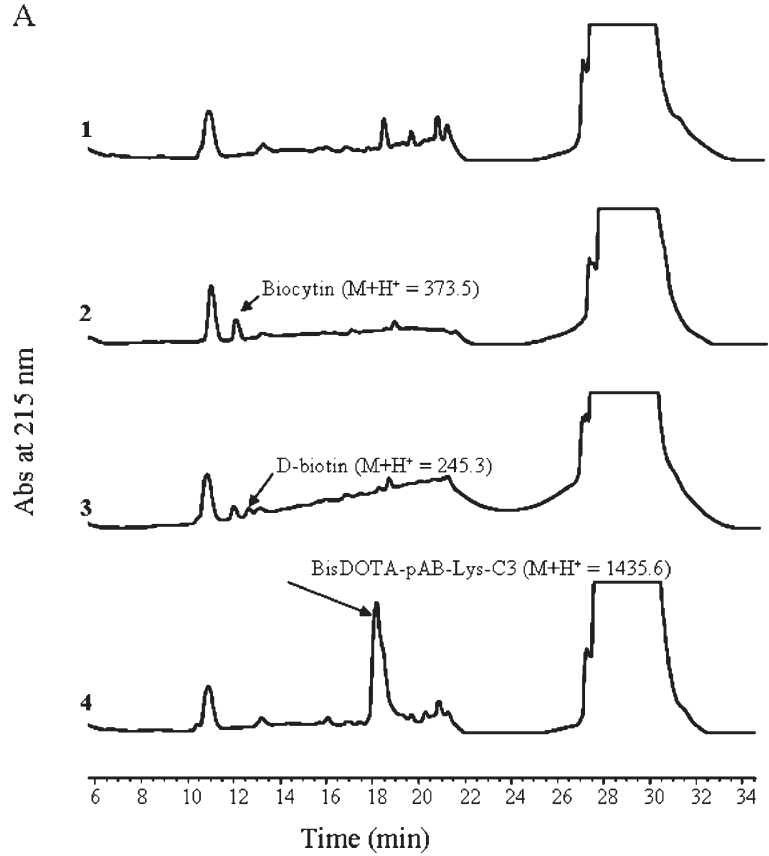

$\mathrm{B}$

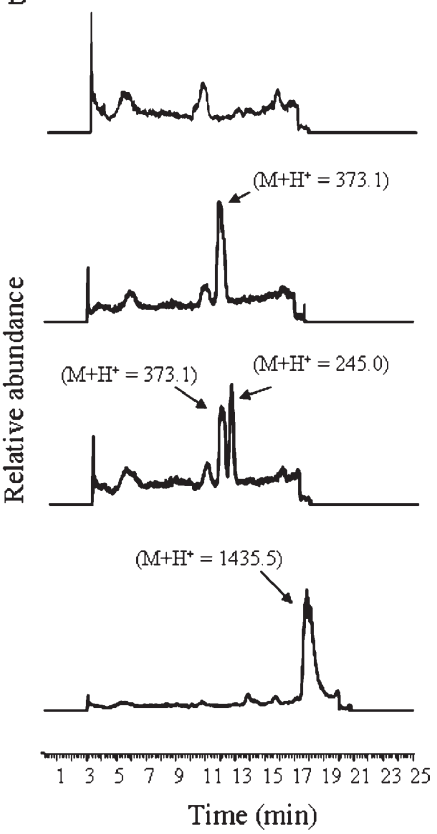

Figure 3. LC-MS analyses of BisDOTA derivatives resistance to biotinidase activity: (A) UV chromatograms from $\mathrm{C}_{2}-\mathrm{C}_{18}$ RP-HPLC column; (B) total ionic current (TIC) from ESI source; (1) NMS; (2) biocytin in NMS at $t=0$ min.; (3) biocytin in NMS incubated for $2 \mathrm{~h}$ at $37^{\circ} \mathrm{C}$; (4) BisDOTA-Lys-(pAB)- $\mathrm{C}_{3}$ in NMS incubated for $2 \mathrm{~h}$ at $37^{\circ} \mathrm{C}$. In panel A arrows indicate the identified species, with their theoretical molecular weight as protonated species reported in parentheses and expressed in daltons. In panel B arrows indicate the corresponding molecular weights experimentally assigned and expressed in daltons.

bombardment mass spectrum (FAB-MS) was registered on a Finnigan-MAT TSQ70 triple stage quadrupole apparatus equipped with an Ion Tech (Teddington, U.K.) atom gun with xenon as bombarding gas and on a VG 70-250 FAB-MS spectrometer (Micromass). The purity of the final compounds $(>95 \%)$ was checked by HPLC and, in some cases, also by combustion analysis, performed on a Perkin-Elmer $240 \mathrm{C}$ elemental analyzer.

Chromatography. TLC was carried out on $\mathrm{SiO}_{2}$ (Merck, $60 \AA$ $\left.\mathrm{F}_{254}\right)$, and spots were located with UV light (254 and $366 \mathrm{~nm}$ ), methanolic ninhydrin, Fluram (Fluka; fluorescamine, 4-phenylspyro[furan-2(3H), $1^{\prime}$-isobenzofuran]-3,3'-dione) in acetone, $\mathrm{Cl}_{2} / \mathrm{O}$-tolidine [O-tolidine $(75 \mathrm{mg})$ ], $\mathrm{AcOH}(3 \mathrm{~mL})$, and $\mathrm{KI}(21$ $\mathrm{mg}$ ) in water $(47 \mathrm{~mL})$. SPE was performed on RP-LiChroprep resins, and FCC purifications were performed on silica gel 60 , $40-63 \mu \mathrm{m}$, as detailed in the text. Semipreparative HPLC was carried out by a Supelco $\mathrm{C}_{18} 180 \AA(250 \mathrm{~mm} \times 10 \mathrm{~mm}, 5 \mu \mathrm{m}$, metals $<10 \mathrm{ppm}$ ) colum at $28^{\circ} \mathrm{C}$ using a Beckman Gold Noveau instrument (detector diode array). Analytical HPLC was run on $5 \mu \mathrm{m}$ Phenomenex Jupiter columns $\mathrm{C}_{18} 300 \AA(250 \mathrm{~mm} \times 4.6$ $\mathrm{mm})$. The solvent systems used for gradients were A $(0.1 \% \mathrm{TFA}$ in $\left.\mathrm{H}_{2} \mathrm{O}\right)$ and $\mathrm{B}\left(0.1 \%\right.$ TFA in $\left.\mathrm{CH}_{3} \mathrm{CN}\right)$. The flow rates were $1 \mathrm{~mL} / \mathrm{min}$ for analytical HPLC and $4 \mathrm{~mL} / \mathrm{min}$ for semipreparative HPLC, with the linear gradients indicated when necessary. LC-ESI MS analyses were performed by a Phenomenex Aqua $\mathrm{C}_{18}$ column $(5 \mu \mathrm{m}, 150 \mathrm{~mm} \times 2.0 \mathrm{~mm})$ (flow rate, $200 \mu \mathrm{L} / \mathrm{min}$ ) or a Vydac $218 \mathrm{MS} 51 \mathrm{C}_{18}$ mass spectometry column $(5 \mu \mathrm{m}$, $250 \mathrm{~mm} \times 1.0 \mathrm{~mm}$ ) (flow rate, $300 \mu \mathrm{L} / \mathrm{min}$ ) on a Thermo Finnigan Surveyor HPLC system coupled to the ESI-MS, using the solvent systems $\mathrm{H}_{2} \mathrm{O}(\mathrm{A}), \mathrm{MeCN}(\mathrm{B}), 1 \%$ TFA in $\mathrm{H}_{2} \mathrm{O}(\mathrm{C})$. Silica gel ITLC paper strips for the labeling procedure were from ITLC-SG, Gelman Science, Ann Arbor, MI. The radiochromatographic profile was determined by Cyclone (Packard BioScience, Meriden, CT). For determination of the serum stability, the apparatus was a $\mathrm{C}_{2}-\mathrm{C}_{18}$ RP-HPLC column (2.1 $\mathrm{mm} \times 100 \mathrm{~mm}, \mathrm{GE}$ Healthcare) connected to a LC-ESI-MS system (LCQ Duo, Thermo-Finnigan). The solvent systems used were $\mathrm{A}\left(0.08 \%\right.$ TFA in $\left.\mathrm{H}_{2} \mathrm{O}\right)$ and $\mathrm{B}(0.08 \%$ TFA in $\left.\mathrm{CH}_{3} \mathrm{CN}\right)$.
Synthesis of BisDOTA-C 3 (5a). Bis[(9H-fluoren-9-yl)methyl]$3,3^{\prime}$-[2-oxo-2-[[6-[[5-[(3aS,4S,6aR)-hexahydro-2-oxo- $1 H$-thieno[3,4-d] imidazol-4yl]pentyl] amino] hexyl]amino]ethylazanodiyl] Bis(propane-1,3-diyl) Dicarbamate (3a). The compound was obtained by adding the activated $(+)$-biotin ( 2 mol equiv) in two steps to a solution of 2a in NMP and stirring for $5 \mathrm{~h}$ at room temperature. The product was purified by SPE (LiChroprep $\mathrm{RP}_{8}, 40-63 \mu \mathrm{m} ; 170 \mathrm{~mm} \times 20 \mathrm{~mm}$; eluent, $\mathrm{CH}_{3} \mathrm{CN} / \mathrm{H}_{2} \mathrm{O} / \mathrm{HCl}=$ 50:50:0.1, $1 \mathrm{~mL} / \mathrm{min}$ ), and the yellow-orange oil was checked by TLC inspection $\left(\mathrm{CH}_{3} \mathrm{CN} / \mathrm{H}_{2} \mathrm{O} / \mathrm{HCl}=50: 50: 0.1\right)$. Analytical HPLC $(30-100 \%$ of B in $20 \mathrm{~min}): t_{\mathrm{R}}=15.4 \mathrm{~min} .{ }^{1} \mathrm{H}$ NMR $(298$ K), $\delta$ (DMSO- $\left.d_{6}, 200 \mathrm{MHz}\right): 9.63$ (br s, $\left.1 \mathrm{H}\right), 8.64$ (br s, 3H), 7.87 (d, 4H), $7.65(\mathrm{~d}, 4 \mathrm{H}), 7.43-7.27(\mathrm{~m}, 8 \mathrm{H}), 6.41(\mathrm{~d}, 2 \mathrm{H}), 4.31-4.14$ $(\mathrm{m}, 8 \mathrm{H}), 3.85(\mathrm{~s}, 2 \mathrm{H}), 3.14-3.03(\mathrm{~m}, 11 \mathrm{H}), 2.82-2.76(\mathrm{~m}, 4 \mathrm{H})$, $2.6(\mathrm{~d}, 2 \mathrm{H}), 1.76-1.25(\mathrm{~m}, 20 \mathrm{H})$. ESI-MS (positive ions): $m / z$ calcd $[\mathrm{M}+\mathrm{H}]^{+}$944.5; found $944.5[\mathrm{M}+\mathrm{H}]^{+}$.

2-[Bis(3-aminopropyl)amino]- $N$-[6-[[5-[(3aS,4S,6aR)-hexahydro-2-oxo- $1 H$-thieno[3,4- $d]$ imidazol-4-yl]pentyl]amino]hexyl]acetamide (4a). The compound was obtained after evaporation of DMF solution, dissolved in $\mathrm{MeOH}$, and precipitated by ethyl ether. The solid, dissolved in $\mathrm{H}_{2} \mathrm{O}$ and lyophilized, was then purified by SPE (LiChroprep $\mathrm{RP}_{18}, 25-40 \mu \mathrm{m}, 170 \mathrm{~mm} \times 20$ $\mathrm{mm}$; eluent, $\mathrm{H}_{2} \mathrm{O} / 100 \%-\mathrm{MeOH} 4-100 \%$ ). The pure compound was collected from the aqueous fractions as a colorless solid. Analytical HPLC (5-15\% of B in $30 \mathrm{~min}): t_{\mathrm{R}}=18.2 \mathrm{~min}$. ${ }^{1} \mathrm{H}$ NMR $(298 \mathrm{~K}), \delta\left(\mathrm{CDCl}_{3}, 200 \mathrm{MHz}\right): 8.12$ (br s, $\left.2 \mathrm{H}\right), 6.45$ $(\mathrm{s}, 2 \mathrm{H}), 4.35-4.25(\mathrm{~m}, 1 \mathrm{H}), 4.15-4.05(\mathrm{~m}, 1 \mathrm{H}), 3.59-2.95(\mathrm{~m}$, $7 \mathrm{H}), 2.95-2.70(\mathrm{~m}, 12 \mathrm{H}), 2.50(\mathrm{~d}, 2 \mathrm{H}), 1.80-1.20(\mathrm{~m}, 20 \mathrm{H})$. ESI-MS (positive ions): $m / z$ calcd $[\mathrm{M}+\mathrm{H}]^{+} 499.4$; found 500.4 $[\mathrm{M}+\mathrm{H}]^{+}$.

2,2', $2^{\prime \prime}$-[10-[2,9-Dioxo-22-[(3aS,4S,6aR)-hexahydro-2-oxo- $1 H$ thieno[3,4- $d$ ] imidazol-4-yl]-7-[3-[2-[4,7,10-tris(carboxymethyl)-1,4, 7,10-tetraazacyclododecane- $N$-1-yl] acetamide]propyl]-3,7,10,17tetraazadocosyl]-1,4,7,10-tetraazacyclododecane- $N^{\prime}, N^{\prime \prime}, N^{\prime \prime \prime}-1,4$, 7-triyl]triacetic Acid (5a). After the coupling of $\mathbf{4 a}$ with DOTA, the aqueous solution was evaporated to dryness and the crude compound was purified by SPE as for $\mathbf{4 a}$. Crude $\mathbf{5 a}$ was collected from the methanolic solution and further purified by semipreparative RP-HPLC, affording the pure compound as a colorless 
solid. ${ }^{1} \mathrm{H}$ NMR (298 K), $\delta\left(\mathrm{D}_{2} \mathrm{O}, 400 \mathrm{MHz}\right): 4.51-4.48(\mathrm{~m}, 1 \mathrm{H})$, 4.32-4.29 (m, 1H), 3.92 (br s, 2H), 3.72-2.65 (m, 65H), 1.81-1.23 (m, 20H). ESI-MS (positive ions): $m / z$ calcd $[\mathrm{M}+$ $\mathrm{H}]^{+} 1272.73,[\mathrm{M}+2 \mathrm{H}]^{2+} 636.86(100 \%)$; found $1272.71[\mathrm{M}+$ $\mathrm{H}]^{+}, 637.2[\mathrm{M}+2 \mathrm{H}]^{2+}$. Anal. $\left(\mathrm{C}_{56} \mathrm{H}_{101} \mathrm{~N}_{15} \mathrm{O}_{16} \mathrm{~S} \cdot 6 \mathrm{TFA} \cdot 5 \mathrm{H}_{2} \mathrm{O}\right)$ $\mathrm{C}, \mathrm{H}, \mathrm{N}$.

Synthesis of the $\mathbf{C}_{6}$-Chain Spacer (2b). 2,2' -(Iminodi-6,1-hexanediyl)bis-1 $H$-isoindole-1,3(2H)-dione $(7)$. The compound was collected as an orange oil and used in the next step without further purification. ${ }^{1} \mathrm{H}$ NMR $(298 \mathrm{~K}), \delta\left(\mathrm{CDCl}_{3}, 200 \mathrm{MHz}\right)$ : $7.81-7.77(\mathrm{~m}, 4 \mathrm{H}), 7.68-7.64(\mathrm{~m}, 4 \mathrm{H}), 3.62(\mathrm{t}, 4 \mathrm{H}), 2.57(\mathrm{t}, 4 \mathrm{H})$, $2.20(\mathrm{~s}, 1 \mathrm{H}), 1.75-1.55(\mathrm{~m}, 4 \mathrm{H}), 1.5-1.4(\mathrm{~m}, 8 \mathrm{H}), 1.35-1.2(\mathrm{~m}$, $4 \mathrm{H})$. ESI-MS (positive ions): $m / z$ calcd $[\mathrm{M}+\mathrm{H}]^{+} 476.3$; found $476.5[\mathrm{M}+\mathrm{H}]^{+}$

$\mathrm{N}, \mathrm{N}$-Bis[6-(1,3-dihydro-1,3-dioxo-2 $\mathrm{H}$-isoindole-2-yl)hexyl]glycine Ethyl Ester (8). The compound was collected from evaporation of DMF and purified through FCC (eluent, AcOEt/petroleum ether $=1: 1$ ), affording 8 as an yellow-orange oil. Analytical HPLC (30-80\% of B in $20 \mathrm{~min}), t_{\mathrm{R}}=15.6 \mathrm{~min}$. ${ }^{1} \mathrm{H}$ NMR $(298 \mathrm{~K}), \delta\left(\mathrm{CDCl}_{3}, 200 \mathrm{MHz}\right): 7.81-7.75(\mathrm{~m}, 4 \mathrm{H})$, $7.70-7.64(\mathrm{~m}, 4 \mathrm{H}), 4.10(\mathrm{q}, 2 \mathrm{H}), 3.62(\mathrm{t}, 4 \mathrm{H}), 3.24(\mathrm{~s}, 2 \mathrm{H}), 2.49(\mathrm{t}$, 4H), 1.66-1.56 (m, 4H), 1.44-1.26 (m, 15H). ESI-MS (positive ions): $m / z$ calcd $[\mathrm{M}+\mathrm{H}]^{+} 562.3$; found $562.4[\mathrm{M}+\mathrm{H}]^{+}$.

$\mathrm{N}, \mathrm{N}$-Bis(6-aminohexyl)glycine (9). Analytical HPLC (20$60 \%$ of $\mathrm{B}$ in $20 \mathrm{~min}): t_{\mathrm{R}}=6.47 \mathrm{~min} .{ }^{1} \mathrm{H} \mathrm{NMR}(298 \mathrm{~K}), \delta$ (DMSO- $d_{6}, 200 \mathrm{MHz}$ ): 10.22 (br s, $\left.1 \mathrm{H}\right), 8.18$ (br s, 4H), 4.06 (s, $2 \mathrm{H}), 3.13-3.08(\mathrm{~m}, 4 \mathrm{H}), 2.8-2.55(\mathrm{~m}, 4 \mathrm{H}), 1.58-1.55(\mathrm{~m}, 8 \mathrm{H})$, $1.4-1.15(\mathrm{~m}, 8 \mathrm{H})$. ESI-MS (positive ions): $m / z$ calcd $[\mathrm{M}+\mathrm{H}]^{+}$ 274.3; found $274.3[\mathrm{M}+\mathrm{H}]^{+}$

$\mathrm{N}, \mathrm{N}$-Bis[[[6-(9H-fluoren-9-ylmethoxy)carbonyl] amino $]$ hexyl]glycine (2b). The compound was extracted from the reaction solution previously acidified with $3 \mathrm{M} \mathrm{HCl}$. The crude product was purified by FCC (eluent, $\mathrm{CHCl}_{3} / \mathrm{MeOH}=3: 1$ ) to provide compound $\mathbf{2 b}$. Analytical HPLC (30-100\% of B in $20 \mathrm{~min}): t_{\mathrm{R}}$ $=19.67 \mathrm{~min} .{ }^{1} \mathrm{H}$ NMR $(298 \mathrm{~K}), \delta\left(\mathrm{CDCl}_{3}, 400 \mathrm{MHz}\right): 7.71(\mathrm{~d}$, $4 \mathrm{H}), 7.56(\mathrm{~d}, 4 \mathrm{H}), 7.38-7.22(\mathrm{~m}, 8 \mathrm{H}), 4.33-4.29(\mathrm{~m}, 2 \mathrm{H}), 4.16$ $(\mathrm{d}, 4 \mathrm{H}), 3.60-3.44(\mathrm{~m}, 2 \mathrm{H}) 3.3-2.95(\mathrm{~m}, 8 \mathrm{H}), 1.72-1.20(\mathrm{~m}$, $16 \mathrm{H})$. ESI-MS (positive ions): $m / z$ calcd $[\mathrm{M}+\mathrm{H}]^{+} 718.4,[2 \mathrm{M}+$ $\mathrm{H}]^{+}$1434.8; found $718.4[\mathrm{M}+\mathrm{H}]^{+}, 1435.1[2 \mathrm{M}+\mathrm{H}]^{+}$.

Synthesis of BisDOTA-C 6 (5b). $N, N$-Bis $[(9 H$-fluoren-9yl)methyl $] 3,3^{\prime}$-[2-oxo-2-[[6-[[5-[(3a $\left.S, 4 S, 6 \mathrm{a} R\right)$-hexahydro-2-oxo$1 H$-thieno[3,4- $d$ ]imidazol-4-yl]pentyl]amino]hexyl]amino]ethylazanodiyl]bis(hexan-1,6-diyl)dicarbamate (3b). After evaporation of NMP under reduced pressure, the oily residue was treated with $\mathrm{H}_{2} \mathrm{O}$ and then purified by SPE (LiChroprep $\mathrm{RP}_{8}$, $40-63 \mu \mathrm{m}, 170 \mathrm{~mm} \times 20 \mathrm{~mm}$; eluent, $\mathrm{H}_{2} \mathrm{O} / \mathrm{CH}_{3} \mathrm{CN}=2: 3,1 \mathrm{~mL} /$ min), affording compound $\mathbf{3 b}$. Analytical HPLC as for $\mathbf{2 b}: t_{\mathrm{R}}=$ $16.57 \mathrm{~min} .{ }^{1} \mathrm{H}$ NMR $(298 \mathrm{~K}), \delta$ (DMSO- $\left.d_{6}, 200 \mathrm{MHz}\right)$ : 7.84-7.20; Fmoc. ESI-MS (positive ions): $m / z$ calcd $[\mathrm{M}+\mathrm{H}]^{+}$ 1028.6; found $1028.5[\mathrm{M}+\mathrm{H}]^{+}$.

2-[Bis(6-aminohexyl)amino]- $N$-[6-[[5-[(3a $S, 4 S, 6 a R)$-hexahydro2-oxo-1 $H$-thieno[3,4- $d]$ imidazol-4-yl $]$ pentyl $]$ amino $]$ hexyl $]$ acetamide (4b). The crude compound was collected and purified as reported for 4a. However, from the SPE eluate the pure product was found in the methanolic fraction as a colorless solid. Analytical HPLC (5-30\% of B in $30 \mathrm{~min}): t_{\mathrm{R}}=18.48 \mathrm{~min} .{ }^{1} \mathrm{H} \mathrm{NMR} \delta$ (DMSO- $d_{6}, 200 \mathrm{MHz}$ ): Fmoc signals disappeared. ESI-MS (positive ions): $m / z$ calcd $[\mathrm{M}+\mathrm{H}]^{+} 584.5$; found $584.7[\mathrm{M}+\mathrm{H}]^{+}$.

2,2', 2' -[10-[16-Carboxy-2,9-dioxo-22-[(3a $, 4 S, 6 a R)$-hexahydro-2-oxo-1 $H$-thieno[3,4- $d]$ imidazol-4-yl]-7-[6-[2-[4,7,10-tris(carboxymethyl)-1,4,7,10-tetraazacyclododecane- $N$-1-yl]acetamide]hexyl]-3,7,10,17-tetraazadocosyl]-1,4,7,10-tetraazacyclododecane- $N^{\prime}, N^{\prime \prime}, N^{\prime \prime \prime}-1,4,7$-triyl]triacetic Acid (5b). The workup was carried out as reported for compound 5a. Analytical HPLC as for $\mathbf{4 b}: t_{\mathrm{R}}=19.8 \mathrm{~min} .{ }^{1} \mathrm{H}$ NMR $(298 \mathrm{~K}), \delta\left(\mathrm{D}_{2} \mathrm{O}, 400 \mathrm{MHz}\right)$ : 4.55-4.50 (m, 1H), 4.33-4.30 (m, 1H), 3.98 (br s, 2H), 3.89-2.64 (m, 65H), 1.94-1.14 (m, 32H). ESI-MS (positive ions): $m / z$ calcd $[\mathrm{M}+\mathrm{H}]^{+}$1356.82, $[\mathrm{M}+2 \mathrm{H}]^{2+} 678.91$; found $1356.7[\mathrm{M}+\mathrm{H}]^{+}, 679.2[\mathrm{M}+2 \mathrm{H}]^{2+}(100 \%)$. Anal. $\left(\mathrm{C}_{62} \mathrm{H}_{113} \mathrm{~N}_{15} \mathrm{O}_{16} \mathrm{~S} \cdot 9 \mathrm{HCl} \cdot 8 \mathrm{H}_{2} \mathrm{O}\right) \mathrm{C}, \mathrm{H}, \mathrm{N}$.
Synthesis of BisDOTA-Lys- $C_{3}$ (12) and BisDOTALys-(pAB)- $\mathbf{C}_{3}$ (16). The products were synthesized using the classical SPPS method, on Fmoc-Lys(MTT)-Wang resin using the manual synthesizer PLS $4 \times 4$. Each coupling step was checked by performing a Kaiser test on microcleavages. ${ }^{24}$ Briefly, the biotin was coupled to the deprotected lysine according to the TBTU/HOBt/NMM activation method, using a 2fold molar excess of activated biotin. The removal of MTT group was performed with a solution of $1 \%$ TFA in DCM, containing $5 \%$ TIS as scavenger. The spacers $\mathbf{2 a}$ and $\mathbf{1 3}$ were introduced by adding 2-fold molecular excess of the activated reagents, while the DOTA amount was 4 mol equiv. The intermediate compounds were checked by microcleavages and HPLC-MS spectra of the isolated compounds. After the DOTA coupling, the cleavage solution was concentrated under nitrogen fluxing, $\mathrm{Et}_{2} \mathrm{O}$ was added, and the suspension was centrifuged and lyophilized. The crude products were purified by RP-HPLC $(5-30 \%$ of $\mathrm{B}$ in $30 \mathrm{~min})$. The yields were calculated on the basis of the resin loading.

$2,2^{\prime}, 2^{\prime \prime}$-[10-[16-Carboxy-2,9-dioxo-22-[(3a $\left.S, 4 S, 6 a R\right)$-hexahydro-2-oxo- $1 H$-thieno $[3,4-d]$ imidazol-4-yl]-7-[3-[2-[4,7,10-tris(carboxymethyl)-1,4,7,10-tetraazacyclododecan- $\mathrm{N}$-1-yl]acetamido]propyl]-3,7,10,17-tetraazadocosyl]-1,4,7,10-tetraazacyclododecane- $N^{\prime}, N^{\prime \prime}, N^{\prime \prime \prime}-1,4,7$-triyl]triacetic Acid (12). Analytical HPLC was performed as for $\mathbf{5 b}: t_{\mathrm{R}}=11.1 \mathrm{~min} .{ }^{1} \mathrm{H}$ NMR $(298$ $\mathrm{K}), \delta\left(\mathrm{D}_{2} \mathrm{O}, 400 \mathrm{MHz}\right): 4.51-4.48(\mathrm{~m}, 1 \mathrm{H}), 4.32-4.29(\mathrm{~m}, 1 \mathrm{H})$ $4.23-4.19(\mathrm{~m}, 1 \mathrm{H}), 3,93-2.68(\mathrm{~m}, 63 \mathrm{H}), 2.21(\mathrm{t}, 2 \mathrm{H}), 1.84-1.29$ (m, 16H). ESI-MS (positive ions): $m / z$ calcd $[\mathrm{M}+\mathrm{H}]^{+} 1316.68$, $[\mathrm{M}+2 \mathrm{H}]^{2+} 658.84$; found $1316.5[\mathrm{M}+\mathrm{H}]^{+}, 659.2[\mathrm{M}+2 \mathrm{H}]^{2+}$ $(100 \%)$. Anal. $\left(\mathrm{C}_{56} \mathrm{H}_{97} \mathrm{~N}_{15} \mathrm{O}_{19} \mathrm{~S} \cdot 6 \mathrm{H}_{2} \mathrm{O} \cdot 6 \mathrm{TFA}\right) \mathrm{C}, \mathrm{H}, \mathrm{N}$.

2,2', $2^{\prime \prime}$-[10-[2-[3-[[3-[2-[4,7,10-Tris(carboxymethyl)-1,4,7,10tetraazacyclododecan- $N$-1-yl] acetamido]propyl] [2-[4-[5-carboxy5-[5-(2-oxohexahydro-1 $H$-thieno[3,4- $d]$ imidazol-4-yl)pentanamido]pentylcarbamoyl]phenylamino]-2-oxoethyl]amino]propylamino]2-oxoethhyl]-1,4,7,10-tetraazacyclododecane- $N^{\prime}, N^{\prime \prime}, N^{\prime \prime \prime}-1,4$, 7-triyl]triacetic Acid (16). Analytical HPLC conditions were as for 12: $t_{\mathrm{R}}=12.97 \mathrm{~min} .{ }^{1} \mathrm{H}$ NMR $(298 \mathrm{~K}), \delta\left(\mathrm{D}_{2} \mathrm{O}, 400 \mathrm{MHz}\right)$ : $7.70-7.52(\mathrm{dd}, 4 \mathrm{H}), 4.44-4.41(\mathrm{~m}, 1 \mathrm{H}), 4.26-4.23(\mathrm{~m}, 1 \mathrm{H})$, $4.20-4.18(\mathrm{~m}, 1 \mathrm{H}), 3.70-3.06(\mathrm{~m}, 60 \mathrm{H}), 2.83-2,80(\mathrm{~m}, 2 \mathrm{H})$, $2.62-2.58(\mathrm{~m}, 1 \mathrm{H}), 2.15-2.10(\mathrm{~m}, 2 \mathrm{H}), 1.91-1.12(\mathrm{~m}, 16 \mathrm{H})$. ESI MS (positive ions): $m / z$ calcd $[\mathrm{M}+\mathrm{H}]^{+} 1435.72,[\mathrm{M}+2 \mathrm{H}]^{2+}$ 718.86; found $1436.6[\mathrm{M}+\mathrm{H}]^{+}, 718.9[\mathrm{M}+2 \mathrm{H}]^{2+}(100 \%)$. Anal. $\left(\mathrm{C}_{63} \mathrm{H}_{102} \mathrm{~N}_{16} \mathrm{O}_{20} \mathrm{~S} \cdot 7 \mathrm{H}_{2} \mathrm{O} \cdot 8 \mathrm{TFA}\right) \mathrm{C}, \mathrm{H}, \mathrm{N}$.

HABA Assay. Preliminary experiments were performed by varying the concentration of HABA (from $3 \mathrm{mM}$ to $0.3 \mu \mathrm{M}$ ) and avidin $(15.1,7.6$, and $3.8 \mu \mathrm{M})$ to calculate their optimal concentrations in the competitive binding studies. In the final experiments, carried out in $1 \mathrm{~mL}$ sample cuvettes, various concentrations of competitors [(+)-biotin and BisDOTA derivatives] were added to the HABA/Av complex, obtained by mixing avidin and HABA to a final concentration of 7.6 and $0.25 \mu \mathrm{M}$, respectively. Changes in absorbance were measured at $500 \mathrm{~nm}$. All experiments were in triplicate, and the \% inhibition was calculated as $\{[$ (absorbance with competitor) - (absorbance without HABA)/(Av complex)]/[(absorbance without competitor) - (absorbance without $\mathrm{HABA}) /($ Av complex $)]\} \times$ 100.

CD Assay on Avidin/Bis-DOTA Complexes Stability. Each spectrum $(195-260 \mathrm{~nm})$ was obtained from averaging three scans and subtracting the contribution from the buffer solution. Other experimental settings were as follows: $20 \mathrm{~nm} \times$ min scan speed, $2.0 \mathrm{~nm}$ bandwidth, $0.2 \mathrm{~nm}$ resolution, 50 mdeg sensitivity, and $4 \mathrm{~s}$ response. Melting curves of wild type avidin, with or without 4 equiv of D-biotin and its BisDOTA derivatives, were recorded by following the decrease of dichroic signal at $225 \mathrm{~nm}$, keeping the temperature in the range $25-95^{\circ} \mathrm{C}$. Instrument settings were as follows: bandwidth $1 \mathrm{~nm}$, response $0.5 \mathrm{~s}$, data pitch $1{ }^{\circ} \mathrm{C}$, temperature slope $10{ }^{\circ} \mathrm{C} / \mathrm{min}$. At every temperature increment of $5^{\circ} \mathrm{C}$, a far-UV CD spectrum was collected in the experimental conditions reported above. 
General Radiolabeling Procedure. Radiolabeling general procedure was performed using the three derivatives BisDOTA- $\mathrm{C}_{3}$ (5a), BisDOTA-Lys- $\mathrm{C}_{3}$ (12), and BisDOTA-Lys-(pAB)- $\mathrm{C}_{3}(\mathbf{1 6})$ at a concentration of $3 \mathrm{mg} / \mathrm{mL}$ in saline. Equal volumes of $1.0 \mathrm{M}$ sodium acetate buffer ( $\mathrm{pH}$ 5.0) and of the radionuclide chloride solution were used. In each experiment, biotin solution was added to the buffer and transferred into the radionuclide supplier vial. The mixture was then mixed and heated at $95{ }^{\circ} \mathrm{C}$ for $30 \mathrm{~min}$. RCP was assayed in triplicate for each radiolabeled sample by ITLC. An aliquot (usually $0.05 \mathrm{~mL}$ ) of the radiolabeling solution was mixed with $0.2 \mathrm{~mL}$ of an avidin-DTPA solution (0.4 mM Av and 2.5 mM DTPA, final pH 6.0) and kept at room temperature for $5 \mathrm{~min}$. Subsequently, an amount of 5 $\mu \mathrm{L}$ of the radioactive mixture was spotted on a silica gel ITLC paper strip and then developed in saline solution. In this chromatographic system, Av-radio-biotin complex remains at the origin whereas free radiometal, bound to DTPA, migrates to the solvent front. The radiochromatographic profile was determined by an autoradiographic system using high performance storage phosphor screen and RCP consequently calculated. Labeling yields greater than $97 \%$ were routinely achieved.

High Specific Activity (SA) Radiolabeling. To determine the achievable SA (expressed as $\mathrm{MBq} / \mathrm{nmol}$ ), the three derivatives 5a, 12, and $\mathbf{1 6}$ were radiolabeled with ${ }^{90} \mathrm{Y}$ at the following increasing of SA: 2.6, 5.2, 10.6, 51.2, 212, $530 \mathrm{MBq} / \mathrm{nmol}$. RCP was determined in each sample as previously described.

Serum Stability. Normal mouse serum, freshly collected just before each experiment, was used as the source of biotinidase activity. Each experiment was carried out by mixing $50 \mu \mathrm{L}$ of NMS with $10-25 \mu \mathrm{L}$ of samples (BisDOTA derivatives or Biocytin). The volume was adjusted to $500 \mu \mathrm{L}$ with reaction buffer (100 mM sodium acetate, $\mathrm{pH} 5.5)$, and each sample was incubated at $37^{\circ} \mathrm{C}$ in water bath up to $2 \mathrm{~h}$. To stop the reaction, an amount of $50 \mu \mathrm{L}$ of each sample was diluted 10 -fold with $0.08 \%$ TFA $(v / v)$ in water, either before and after incubation, and $40 \mu \mathrm{L}$ of this solution was applied to the HPLC columns. The chromatographic separations were carried out at a flow rate of $0.2 \mathrm{~mL} /$ min and by applying a gradient from $2 \%$ to $60 \%$ of B in $20 \mathrm{~min}$. Main settings of ESI source were the following: spray voltage, $4.2 \mathrm{kV}$; capillary temperature, $300^{\circ} \mathrm{C}$; capillary voltage, $6 \mathrm{~V}$.

Acknowledgment. The authors aknowledge the IEO of Milan, the Ente Cassa di Risparmio di Firenze, and Italian MIUR (PRIN 2005) for financial support.

Supporting Information Available: Synthesis and purification of BisDOTA-C ${ }_{3}$, spacer- $\mathrm{C}_{6}$, BisDOTA-C 6 , BisDOTA-Lys- $\mathrm{C}_{3}$, and BisDOTA-Lys-(pAB)-C $\mathrm{C}_{3}$; HPLC, analytical, and ESI-MS data. This material is available free of charge via the Internet at http://pubs.acs.org.

\section{References}

(1) Green, N. M. Avidin and Streptavidin. Methods Enzymol. 1990, 184, 51-67.

(2) Sakahara, H.; Saga, T. Avidin-biotin system for delivery of diagnostic agents. Adv. Drug Delivery Rev. 1999, 37, 89-101.

(3) Hamblett, K. J.; Press, O. W.; Meyer, D. L.; Hamlin, D. K.; Axworthy, D.; Wilbur, D. S.; Stayton, P. S. Role of biotin-binding affinity in streptavidin-based pretargeted radioimmunotherapy of lymphoma. Bioconjugate Chem. 2005, 16, 131-138.

(4) Goodwinn, D. A.; Meares, C. F. Advances in pretargeting biotechnology. Biotechnol. Adv. 2001, 19, 435-450.

(5) Chinol, M.; Grana, C.; Gennari, R.; Cremonesi, M.; Geraghty, J. G.; Paganelli, G. Pretargeted Radioimmunotherapy of Cancer. In Radioimmunotherapy of Cancer; Abrams, P. G., Fritzberg, A. R. F., Eds.; Marcel Dekker: New York, 2000; pp 169-193.

(6) Renn, O.; Goodwin, D. A.; Studer, M.; Moran, J. K.; Jacques, V. Meares, C. F. New approaches to delivering metal-labeled antibodies to tumors: synthesis and characterization of new biotinyl chelate conjugates for pre-targeted diagnosis and therapy. J. Controlled Release 1996, 39, 239-249.

(7) Paganelli, G.; Bartolomei, M.; Ferrari, M.; Cremonesi, M.; Brogli, G.; Maira, G.; Sturiale, C.; Grana, C.; Prisco, G.; Gatti, M.; Caliceti, P.; Chinol, M. Pre-targeted locoregional radioimmunoteraphy with $90 \mathrm{Y}$-biotin in glioma patients: phase I study and preliminary therapeutic results. Cancer Biother. Radiopharm. 2001, 16, 227-235.

(8) Wilbur, D. S.; Hamlin, D. K.; Chyan, M. K.; Kegley, B. B.; Pathare, P. M. Biotin reagents for antibody pretargeting. 5. Additional studies of biotin conjugate design to provide biotinidase stability. Bioconjugate Chem. 2001, 12, 616-623.

(9) Grana C. Bartolomei, M ; Handkiewicz, D : Rocca, P : Bodei, L : Colombo, N.; Chinol, M.; Mangioni, C.; Malavasi, F.; Paganelli, G. Radioimmunotherapy in advanced ovarian cancer: there is a role for pretargeting with 90Y-biotin? Gynecol. Oncol. 2004, 93 , 691-698.

(10) Chinol, M.; De Cobelli, O.; Paganelli, G. Localization of avidin in superficial bladder cancer: preliminary results and first therapeutic application using yttrium-90-biotin. Am. J. Urol. Rev. 2004, 2, 190194.

(11) De Santis, R.; Anastasi, A. M.; D'Alessio, V.; Pelliccia, A.; Albertoni, C.; Rosi, A.; Leoni, B.; Lindstet, R.; Petronzelli, F.; Dani, M.; Verdoliva, A.; Ippolito, A.; Campanile, M.; Manfredi, V.; Esposito, A.; Cassani, G.; Chinol, M.; Paganelli, G.; Carminati, P. Novel antitenascin antibody with increased tumour localization for pretargeted antibody-guided radioimmunotherapy (PAGRIT). Br. J. Cancer 2003, 88, 996-1003.

(12) Chinol, M.; De Cobelli, O.; Trifirò, G.; Scardino, E.; Bartolomei, M.; Verweij, F.; Papi, S.; Matei, D. V.; Paganelli, G. Localization of avidin in superficial bladder cancer: a potentially new approach for radionuclide therapy. Eur. Urol. 2003, 44, 556-559.

(13) Paganelli, G.; Grana, C.; Chinol, M.; Cremonesi, M.; De Cicco, C.; De Braud, F.; Robertson, C.; Siccardi, A. G.; Veronesi, U. Antibody guided three-step therapy for high grade glioma with $90 \mathrm{Y}$ biotin. Eur. J. Nucl. Med. 1999, 26, 348-357.

(14) Wilbur, D. S.; Hamlin, D. K.; Chyan, M. K.; Kegley, B. B.; Pathare, P. M. Biotin reagents for antibody pretargeting. 5. Additional studies of biotin conjugate design to provide biotinidase stability. Bioconjugate Chem. 2001, 12, 616-623 and references therein .

(15) Wilbur, D. S.; Hamlin, D. K.; Chyan, M. K.; Kegley, B. B.; Quinn, J.; Vessella, R. L. Biotin reagents in antibody pretargeting. 6. Synthesis and in vivo evaluation of astatinated and radioiodinated aryl- and nido-carboranyl-biotin derivatives. Bioconjugate Chem. 2004, 15, 601-616 and references therein

(16) Axworthy, D. B.; Theodore, L. J.; Gustavson, L. M.; Reno, J. M. Biotinidase-Resistant Biotin-DOTA Conjugates. U.S. Patent 5,608,060, 1997

(17) Hainsworth, J.; Harrison, P.; Mather, S. J. Preparation and characterization of a DOTA-lysine-biotin conjugate as an effector molecule for pretargeted radionuclide therapy. Bioconjugate Chem. 2005, 16, 1468-1474.

(18) Pazy, Y.; Kulik, T.; Bayer, E. A.; Wilchek, M.; Livnah, O. Ligand exchange between proteins. J. Biol. Chem. 2002, 277, 30892-30900.

(19) Sabatino, G.; Chinol, M.; Paganelli, G.; Papi, S.; Chelli, M.; Leone, G.; Papini, A. M.; De Luca, A.; Ginanneschi, M. A new biotin derivative-DOTA conjugate as a candidate for pretargeted diagnosis and therapy of tumors. J. Med. Chem. 2003, 46, 3170-3173.

(20) Carpino, L. A.; Imazumi, H.; El-Faham, A.; Ferrer, F. J.; Zhang, C.; Lee, Y.; Foxman, B. M.; Henklain, P.; Hanay, C.; Mugge, C.; Wenshuh, H.; Klose, J.; Beyermann, M.; Bienert, M. The uronium/ guanidinium peptide coupling reagents: finally the true uronium. Angew. Chem., Int. Ed. 2002, 41, 441-445.

(21) Bambino, F.; Brownlee, R. T. C.; Chiu, F. C. K. Synthesis of a symmetrically branched template for parallel $\alpha$-helix dimers. Tetrahedron Lett. 1994, 35, 4619-4622.

(22) Green, N. M. A spectrophotometric assay for avidin and biotin based on binding of dyes by avidin. Biochem. J. 1965, 94, 23c-24c.

(23) Paganelli, G.; Ferrari, M.; Ravasi, L.; Cremonesi, M.; De Cicco, C.; Galimberti, V.; Sivolapenko, G.; Luini, A.; De Santis, R.; Travaini, L. L.; Fiorenza, M.; Chinol, M.; Papi, S.; Zanna, C.; Carminati, P.; Veronesi, U. Intraopearative avidination for radionuclide therapy: a prospective new development to accelerate radiotherapy in breast cancer. Clin. Cancer Res. 2007, 13 (Suppl. $18), 5646 \mathrm{~s}-5651 \mathrm{~s}$.

(24) Kaiser, E.; Colescott, R. L.; Bossinger, C. D.; Cook, P. I. Color test for detection of free terminal amino groups in the solid-phase synthesis of peptides. Anal. Biochem. 1970, 34, 595-598. 